\title{
Research Paper: Functional Movement Screen in Elite Boy Basketball Players: A Reliability Study
}

Farzaneh Saki ${ }^{\text {* }}$

1. Department of Corrective Exercise and Sport Injury, Faculty of Physical Education and Sport Sciences, Bu-Ali Sina University, Hamedan, Iran.

\begin{tabular}{|c|c|}
\hline $\begin{array}{l}\text { Use vour device to san } \\
\text { and read the article online }\end{array}$ & \\
\hline 口ifing & $\begin{array}{l}\text { Citation: Saki F. Functional Movement Screen in Elite Boy Basketball Players: A Reliability Study. Physical Treatments. } \\
\text { 2017; 6(4):211-216. https://doi.org/10.18869/nrip.ptj.6.4.211 }\end{array}$ \\
\hline 田 & doi': https://doi.org/10.18869/nrip.ptj.6.4.211 \\
\hline
\end{tabular}

Article info:

Received: 05 Jul. 2016

Accepted: 11 Oct. 2016
Keywords:

Functional movement screen, Reliability,

Basketball

\begin{abstract}
A B S T RA C T
Purpose: To investigate the reliability of Functional Movement Screen (FMS) in basketball players. A few studies have compared the reliability of FMS between raters with different experience in athletes. The purpose of this study was to compare the FMS scoring between the beginners and expert raters using video records.

Methods: This is a cross-sectional study. The study subjects comprised 15 elite boy basketball players. The subjects were randomly selected and each of them completed FMS tests. Three examiners (two beginners and one expert) watched the recorded video separately and scored the tests. We used the Kinovea video-analysis software for data analysis. The test-retest reliability was assessed using Intra-Class Correlation Coefficients (ICCs). Also inter-tester reliability of each test was computed using Fleiss' kappa test.
\end{abstract}

Results: The mean (SD) total FMS score for rater 1, rater 2, and rater 3 were 14.17(1.26), 14.17(1.94), and 13.67(1.67), respectively. There was no significant difference between examiners with respect to total FMS score $(\mathrm{P}=0.136)$. Half of the individual FMS components had perfect agreement, and rest were categorized as moderate to substantial agreement. The high and moderate values of ICC as 0.88 0.99 and 0.71 0.91 were observed for intra-rater and interrater reliability, respectively.

Conclusion: The examiners reported FMS total scores similarly. The inter-rater reliability for the test components had strong agreement. This finding suggests that FMS can be used in the evaluation of the abnormal movement patterns of the athletes.

\section{Introduction}

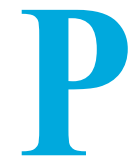

re-participation physical examination is well proposed as a part of the international sport programs and used to identify possible risk factors leading to disease and injury such as sudden cardiac death, cardiovascular disease, and particular musculoskeletal disorders [1-4].
Generally, pre-participation screening methods can be used to evaluate the health condition prior to participation in competition. It focuses on factors that could identify particular athletic talents or predispose athletes to injury [5-9].

Some researchers have reported several intrinsic and extrinsic risk factors, including muscle strength, structural malalignments, sex, postural sway, fitness level, and his-

\section{* Corresponding Author:}

Farzaneh Saki, MSc.

Address: Department of Corrective Exercise and Sport Injury, Faculty of Physical Education and Sport Sciences, Bu-Ali Sina University, Hamedan, Iran. Phone: +98 (918) 8503783

E-mail: F_saki@basu.ac.ir 
tory of previous musculoskeletal injury that predispose athletes to injury [10-12]. Additionally, poor neuromuscular control, weak core stability, and muscular asymmetries have been proposed as other risk factors for injury. Contralateral muscle imbalances may lead to muscular inhibition and compensatory strategies [13].

Functional Movement Screen (FMS) is an effective method that quantitatively measures movement patterns to detect performance asymmetries [14]. Health experts and coaches use FMS to screen the athletes at risk of injury with identification of the asymmetry and abnormal movements [15]. Although FMS has widely been used clinically for evaluating of the muscular asymmetries and flexibility deficits, there is little information or investigation about the FMS reliability in athletes. In addition, the traditional sports medicine methods have focused on specific joints and muscles, but new methods like FMS evaluate functional movement.

FMS could help to identify the athletes at risk of injury and affect the recovery of the injured athletes. At the present time, there is no agreement that which factors are required for the return of the athletes to the sports [16]. However, resume to normal sport activity needs the sensory perceptual motoric integration [7].

It seems that the traditional pre-participation screening methods does not provide the adequate baseline information to assess the individual's preparedness, without evaluating the basic aspects of human movements [7]. Movement screening should be performed with specific performance assessments, since the main objectives of the pre-participation screening are reducing injuries, increasing performance, and promoting the quality of movements.

There are two various classifications of reliability measurement, including intra-rater reliability and inter-rater reliability. The first category of reliability evaluates how well each examiner or rater can frequently or consistently obtain the similar resulting score. In the second reliability category, the examiners are more than one and the degree of agreement compute the extent to which the examiners get the similar resulting score, when they look at the same subject [14].

Few researchers have investigated the inter-rater reliability of the FMS score. Schneiders et al. reported the high reliability between two examiners with the similar level of experience. Also, Minick et al. have reported the high reliability between raters with the same level of experience [5, 17]. Smith et al. have examined reliability of FMS scoring among participants with various levels of experience and obtained high reliability [18]. In a similar study, Gribble et al. investigated the inter-rater reliability between examiners with various level of clinical experience and reported moderate reliability between examiners [19]. In both studies, subjects were healthy populations and few studies have evaluated the FMS reliability in athletes. Therefore, the purpose of this study was to evaluate the inter-examiner reliability of the FMS score among beginners and expert examiners.

\section{Materials and Methods}

\section{Participants}

This study had a cross-sectional design. Study population comprised the elite boy basketball players of Hamedan City in 2015 and out of them, 15 subjects were selected randomly. Subjects were injury free at the time of the tests. Assessment protocol was explained to the study subjects. Three raters, including one expert (expert in sport injury and corrective exercise with 2 years' regular experience at working with FMS) and 2 novices (graduated physical education students) scored the FMS performed by the subjects. An informed consent approved by the Bu-Ali Sina University Ethics Committee was signed by all subjects. Sample size was calculated using $\mathrm{G}$ power software ( $\alpha$ level of 0.05 , a power of $80 \%$, and effect size of 0.5 ).

\section{Procedures}

All subjects performed FMS tests. The FMS included seven tasks to evaluate functional movement ability [7]. The subjects performed these seven tasks as a standard sequence, including overhead squat, hurdle step, in-line lunge, shoulder mobility, active hamstrings flexibility, trunk, and rotary stability test. Also, subjects performed three clearing tasks (lumbar flexion, lumbar extension, and shoulder medial rotation) which evaluate pain. Five of these seven tasks assessed the asymmetry by comparing both sides [20].

The participants performed dynamic warm up before assessments and then executed seven FMS tasks. They were received particular instructions about how properly perform each task. Feedback during the test was prohibited and athlete's movements were recorded by 2 digital video cameras (model PC-1262, Canon) positioned in the sagittal and frontal planes (30 frame/second). All subjects performed each task two times. Kinovea video-analysis software version 0.8.15 was used for data analysis.

Three raters scored the test two month later. One of the raters (expert) rescored the video after a week for computing intra-tester reliability [18]. According to the quality of movement, each task was scored from 0 to 3 . The score of 
Table 1. The Fleiss' kappa scores

\begin{tabular}{cc}
\hline Score & Criteria \\
\hline Excellent & $80 \%$ and higher \\
\hline Substantial & $60 \%$ to $79.9 \%$ \\
\hline Moderate & $40 \%$ to $59.9 \%$ \\
\hline Poor & Below $40 \%$ \\
\hline
\end{tabular}

PHYSICAL TREA TMENTS

3 was given to the participant who was able to execute each task without compensatory motion. The participant, who performed the task with compensation motion received a score 2 . The score of 1 was given to the participant who was unable to obtain the position to perform task. The participant, who experienced pain during the task, received a 0 score. The total score was computed by summation of each task score, which ranged from 0 to $21[7,16]$.

\section{Statistical analysis}

Data were analyzed by SPSS 20. The Shapiro-Wilks test was used to assess the data normality distribution. The ICC (Intraclass Correlation Coefficients) was utilized to compute the inter- and intra-rater reliability of total FMS scores. The ICC value changes from 0 to 1 [21]. The inter-tester reliability of each task was assessed by the Fleiss' kappa (Table 1).

\section{Results}

Table 2 presents the demographic information of the subjects. The mean (SD) total score of FMS in all examiners is about 14.06(1.6). Table 3 shows the mean (SD) scores of total FMS and its components for each rater. The ICC value for total scores was $0.87(0.71 \sim 0.91)$ which demonstrates good to excellent agreement between examiners (Table 4). In 12 individual tests, five tests exhibited excellent agreement between the raters, three tests substantial agreement, three tests moderate agreement, and one test poor agreement (Table 5).

\section{Discussion}

The study findings indicate no significant difference in total FMS scores between raters. On the contrary, the ability of three raters in FMS scoring was similar. Also, the total FMS scores of the three evaluators showed excellent correlation. This is in agreement with earlier research. There is a high correlation between the raters in total FMS scoring based on Schneiders et al. study [5]. In addition, Smith et al. and Onate and Dewey reported high inter-rater reliability in their studies $[18,22]$. The mean total FMS score of the present study is similar to the findings of Smith et al. and Chorba et al. studies [13, 18].

We also evaluated inter-rater reliability of the test components and half of the FMS tests showed good agreement based on the study results. Our results are in agreement with previous research on FMS reliability. Minick et al. found significant to good inter-rater agreement on each FMS component scores when compared 2 beginners and 2 experts [17]. Moreover, the finding of this study indicated that right in-line lunge task had the minimum reliability and right active leg raise task, the maximum reliability. This result is consistent with previous studies [23]. Onate and Dewey reported that right leg raise test had the lowest inter-rater reliability [22] whereas this task in the present study showed $100 \%$ agreement. FMS is a noninvasive tool to assess asymmetry of movement abilities in athletes. The importance of this test is that coaches, athletes, and trainers can learn this test as a useful method for evaluating fundamental movement patterns.

Table 2. Demographic information of subjects

\begin{tabular}{cc}
\hline Variable & Mean \pm SD \\
\hline Age $(\mathrm{y})$ & $16.33 \pm 0.65$ \\
Height $(\mathrm{cm})$ & $181.75 \pm 10.03$ \\
Weight $(\mathrm{kg})$ & $69.50 \pm 0.13$ \\
Experience $(\mathrm{y})$ & $6.25 \pm 1.54$ \\
\hline
\end{tabular}

PHYSICAL TREA TMENTS 
Table 3. Mean \pm SD of total and component FMS scores by all raters

\begin{tabular}{|c|c|c|c|}
\hline Test & Rater 1 & Rater 2 & Rater 3 \\
\hline Deep squat & $2.17 \pm 0.718$ & $2.25 \pm 0.622$ & $2.17 \pm 0.718$ \\
\hline Right hurdle step & $1.92 \pm 0.515$ & $1.92 \pm 0.515$ & $2.00 \pm 0.603$ \\
\hline Left hurdle step & $2.00 \pm 0.426$ & $1.92 \pm 0.289$ & $2.00 \pm 0.426$ \\
\hline Right in-line lunge & $2.17 \pm 0.389$ & $1.92 \pm 0.289$ & $2.33 \pm 0.492$ \\
\hline Left in-line lunge & $2.08 \pm 0.515$ & $2.00 \pm 0.426$ & $2.17 \pm 0.577$ \\
\hline Right shoulder mobility & $2.17 \pm 0.835$ & $2.25 \pm 0.754$ & $2.17 \pm 0.835$ \\
\hline Left shoulder mobility & $2.25 \pm 0.754$ & $2.33 \pm 0.651$ & $2.00 \pm 0.853$ \\
\hline Right hamstring flexibility & $2.17 \pm 0.718$ & $2.17 \pm 0.718$ & $2.17 \pm 0.718$ \\
\hline Left hamstring flexibility & $2.17 \pm 0.577$ & $2.25 \pm 0.622$ & $2.17 \pm 0.577$ \\
\hline Trunk stability & $2.08 \pm 0.669$ & $2.17 \pm 0.718$ & $1.92 \pm 0.793$ \\
\hline Right rotary stability & $1.92 \pm 0.515$ & $1.83 \pm 0.577$ & $1.83 \pm 0.452$ \\
\hline Left rotary stability & $2.00 \pm 0.426$ & $2.08 \pm 289$ & $2.00 \pm 0.426$ \\
\hline Total FMS score & $14.17 \pm 1.26$ & $14.17 \pm 1.94$ & $13.67 \pm 1.60$ \\
\hline
\end{tabular}

PHYSICAL TREA \MENTS

Table 4. Reliability of total FMS Scores

\begin{tabular}{ccc}
\hline Variable & ICC & $95 \% \mathrm{Cl}$ \\
\hline Intrarater (test-retest) & 0.96 & $0.88,0.99$ \\
\hline Interrater & 0.87 & $0.71,0.91$ \\
\hline
\end{tabular}

PHYSICAL TREA TMENTS

Table 5. Agreement of FMS individual test scores (0-3 points)

\begin{tabular}{|c|c|c|c|c|}
\hline Test & Kappa & SE & $95 \% \mathrm{Cl}$ & Agreement \\
\hline Deep squat & 0.90 & 0.127 & $0.65,1.15$ & Excellent \\
\hline Right hurdle step & 0.87 & 0.1272 & $0.62,1.12$ & Excellent \\
\hline Left hurdle step & 0.55 & 0.1304 & $0.29,0.80$ & Moderate \\
\hline Right In-line lunge & 0.05 & 0.1477 & $-0.23,0.34$ & Poor \\
\hline Left In-line lunge & 0.72 & 0.1307 & $0.46,0.98$ & Substantial \\
\hline Right Shoulder mobility & 0.91 & 0.1202 & $0.67,1.14$ & Excellent \\
\hline Left Shoulder mobility & 0.65 & 0.1219 & $0.41,0.89$ & Substantial \\
\hline Right hamstring flexibility & 1 & 0.124 & $0.75,1.24$ & Excellent \\
\hline Left hamstring flexibility & 0.89 & 0.135 & $0.62,1.15$ & Excellent \\
\hline Trunk stability & 0.55 & 0.1206 & $0.31,0.79$ & Moderate \\
\hline Right rotary stability & 0.73 & 0.14 & $0.46,1.01$ & Substantial \\
\hline Left rotary stability & 0.55 & 0.1304 & $0.29,0.80$ & Moderate \\
\hline
\end{tabular}

CI: Confidence Interval

PHYSICAL TREA TMENTS 
We suggest that future studies compare the reliability of real-time and video recorded scoring of the FMS. The real-time scoring system provides quicker feedback on the test execution and decreases the time needed for data interpretation. Since video analyzing and FMS scoring is time consuming, professionals do not use it in the training and games. Real time analysis is more applicable to give effective and rapid feedback to majority of the participants.

The present study supports the reliability of FMS test, which is used to evaluate dysfunction and asymmetry of movement. In addition, the finding of this research indicates that total FMS score is reported similarly between the raters, while the reliability of some test components are not suitable for evaluating the functional movement, especially in raters with different experiences. The functional movement screening methods mainly affect the measures taken for injury prevention and performance enhancement.

The limitation of the present research is the small sample size. Also the raters could observe the video records of participant's FMS test without any restrictions. This limitation in video analysis may affect raters' scoring.

\section{Acknowledgements}

This research did not receive any specific grant from funding agencies in the public, commercial, or not-forprofit sectors.

\section{Conflict of Interest}

The author declared no conflicts of interest.

\section{References}

[1] McCrory P. Preparticipation assessment for head injury. Clinical Journal of Sport Medicine. 2004; 14(3):139-44. doi: 10.1097/00042752-200405000-00006

[2] Mottram S, Comerford M. A new perspective on risk assessment. Physical Therapy in Sport. 2008; 9(1):40-51. doi: 10.1016/j.ptsp.2007.11.003

[3] Brukner P, White S, Shawdon A, Holzer K. Screening of athletes. Clinical Journal of Sport Medicine. 2004; 14(3):169-77. doi: 10.1097/00042752-200405000-00010

[4] Wingfield K, Matheson GO, Meeuwisse WH. Preparticipation evaluation. Clinical Journal of Sport Medicine. 2004; 14(3):109-22. doi: 10.1097/00042752-200405000-00002

[5] Schneiders AG, Davidsson Å, Hörman E, Sullivan SJ. Functional movement screenTM normative values in a young, active population. International Journal of Sports Physical Therapy. 2011; 6(2):75-82. PMCID: PMC3109893

[6] McKeown I, Taylor-McKeown K, Woods C, Ball N. Athletic ability assessment: A movement assessment protocol for athletes. International Journal of Sports Physical Therapy. 2014; 9(7):862-73. PMCID: PMC4275191

[7] Cook G, Burton L, Hoogenboom B. Pre-participation screening: The use of fundamental movements as an assessment of function-part 1. North American Journal of Sports Physical Therapy. 2006; 1(2):62-72. PMCID: PMC2953313

[8] Gabbe BJ, Bennell KL, Wajswelner H, Finch CF. Reliability of common lower extremity musculoskeletal screening tests. Physical Therapy in Sport. 2004; 5(2):90-7. doi: 10.1016/j. ptsp.2004.01.003

[9] Reilly T, Williams AM, Nevill A, Franks A. A multidisciplinary approach to talent identification in soccer. Journal of Sports Sciences. 2000; 18(9):695-702. doi: 10.1080/02640410050120078

[10] Pourmahmoudian P, Minoonejad H, Jamshidi AA, Davati Kazemnia $Y$, Javdaneh N. Investigation of gluteus medius and biceps femoris activity in three plyometric exercises. Physical Treatments-Specific Physical Therapy Journal. 2014; 4(3):133-8.

[11] Saki F, Rajabi R, Tabatabaei F. Relationship between hip and knee strength and knee valgus angle during drop jump in elite female athletes. Physical Treatments-Specific Physical Therapy Journal. 2014; 4(1):39-46.

[12] Gheidi N, Sadeghi H, Talebian Moghadam S, Tabatabaei Ghoshe F, Walter Kernozek T. Kinematics and kinetics predictor of proximal tibia anterior shear force during single leg drop landing. Physical Treatments-Specific Physical Therapy Journal. 2014; 4(2):102-8.

[13] Chorba RS, Chorba DJ, Bouillon LE, Overmyer CA, Landis JA. Use of a functional movement screening tool to determine injury risk in female collegiate athletes. North American Journal of Sports Physical Therapy. 2010; 5(2):47-54. PMCID: PMC2953387

[14] Brigle J. The reliability of the functional movement screen [PhD dissertation]. Toledo: University of Toledo; 2010.

[15] Glaws KR, Juneau CM, Becker LC, Di Stasi SL, Hewett TE. Intra and inter-rater reliability of the Selective Functional Movement Assessment (SFMA). International Journal of Sports Physical Therapy. 2014; 9(2):195-207. PMCID: PMC4004125

[16] Cook G, Burton L, Hoogenboom B. Pre-participation screening: The use of fundamental movements as an assessment of function-Part 2. North American Journal of Sports Physical Therapy. 2006; 1(3):132-9. PMCID: PMC2953359

[17] Minick KI, Kiesel KB, Burton L, Taylor A, Plisky P, Butler RJ. Interrater reliability of the functional movement screen. Journal of Strength and Conditioning Research. 2010; 24(2):479-86. doi: 10.1519/jsc.0b013e3181c09c04

[18] Smith CA, Chimera NJ, Wright NJ, Warren M. Interrater and intrarater reliability of the functional movement screen. Journal of Strength and Conditioning Research. 2013; 27(4):982-7. doi: 10.1519/jsc.0b013e3182606df2 
[19] Gribble PA, Brigle J, Pietrosimone BG, Pfile KR, Webster KA. Intrarater reliability of the functional movement screen. Journal of Strength and Conditioning Research. 2013; 27(4):978-81. doi: 10.1519/jsc.0b013e31825c32a8

[20] Okada T, Huxel KC, Nesser TW. Relationship between core stability, functional movement, and performance. Journal of Strength and Conditioning Research. 2011; 25(1):252-61. doi: 10.1519/jsc.0b013e3181b22b3e

[21] Gulgin H, Hoogenboom B. The functional movement screening (FMS) ${ }^{\mathrm{TM}}$ : An inter-rater reliability study between raters of varied experience. International Journal of Sports Physical Therapy. 2014; 9(1):14-20. PMCID: PMC3924604

[22] Onate JA, Dewey T, Kollock RO, Thomas KS, Van Lunen BL, DeMaio M, et al. Real-time intersession and interrater reliability of the functional movement screen. Journal of Strength and Conditioning Research. 2012; 26(2):408-15. doi: 10.1519/jsc.0b013e318220e6fa

[23] Shultz R, Anderson SC, Matheson GO, Marcello B, Besier T. Test-retest and interrater reliability of the functional movement screen. Journal of Athletic Training. 2013; 48(3):331-6. doi: 10.4085/1062-6050-48.2.11 